\title{
Correction to: The Augmented Movement Platform For Embodied Learning (AMPEL): development and reliability
}

\author{
Lousin Moumdjian $^{1,2,3}$ (D) Thomas Vervust ${ }^{4} \cdot$ Joren Six $^{1} \cdot$ Ivan Schepers $^{1} \cdot$ Micheline Lesaffre $^{1} \cdot$ Peter Feys $^{2,3}(\mathbb{D}$. \\ Marc Leman ${ }^{1}$
}

Published online: 4 January 2021

(c) Springer Nature Switzerland AG 2020

\section{Correction to:}

Journal on Multimodal User Interfaces https://doi.org/10.1007/s12193-020-00354-8

There was an error in the affiliations of the co-authors Dr. Thomas Vervust and Prof. Peter Feys. Their correct affiliations are given in this correction.

Original article corrected.
Publisher's Note Springer Nature remains neutral with regard to jurisdictional claims in published maps and institutional affiliations.

The original article can be found online at https://doi.org/10.1007/ s12193-020-00354-8.

\section{Lousin Moumdjian}

lousin.moumdjian@uhasselt.be

1 IPEM Institute of Psychoacoustics and Electronic Music, Faculty of Arts and Philosophy, Ghent University, 9000 Ghent, Belgium

2 UMSC Hasselt, Pelt, Belgium

3 REVAL Rehabilitation Research Center, Faculty of Rehabilitation Sciences, Hasselt University, 3500 Hasselt, Belgium

4 NaMiFab - UGent Expertise Center for Nano- and Microfabrication, Department of Information Technology and Department of Electronics and Information Systems, Ghent University, Technologiepark-Zwijnaarde 126, 9052 Ghent, Belgium 